\title{
GameFlow 2020: 15 Years of a Model of Player Enjoyment
}

\author{
PENNY SWEETSER, The Australian National University, Australia
}

The original GameFlow model was first published in 2005 and in the last 15 years it has seen thousands of citations and hundreds of applications to designing and evaluating games and gameful experiences. Previous work has sought to test and validate the model by applying it to different game experiences to further understand those experiences and to expose any weaknesses of the model. In this paper, we survey over 200 applications of GameFlow over the last 15 years, to understand how, where, and why the model has been applied. We found that the model has been applied to a diverse set of experiences, domains, platforms, audiences, and used in a variety of ways. This work lays the foundations for targeting the next version of the GameFlow model towards the most valuable and appropriate applications and to define how it fits within the broader landscape of player experience tools.

CCS Concepts: • Human-centered computing $\rightarrow$ Heuristic evaluations; • Software and its engineering $\rightarrow$ Interactive games.

Additional Key Words and Phrases: video games, enjoyment, player experience, GameFlow, heuristics, evaluation, design

ACM Reference Format:

Penny Sweetser. 2020. GameFlow 2020: 15 Years of a Model of Player Enjoyment. In 32ND AUSTRALIAN CONFERENCE ON HUMANCOMPUTER INTERACTION (OzCHI '20), December 2-4, 2020, Sydney, NSW, Australia. ACM, New York, NY, USA, 10 pages. https: //doi.org/10.1145/3441000.3441048

\section{INTRODUCTION}

GameFlow [55] is a model of player enjoyment, consisting of 38 criteria derived from games user experience literature and structured into eight elements that conceptually map to Csikszentmihalyi's [13] concept of flow. In the original GameFlow paper [55], the key elements of player enjoyment in video games were identified by conducting a comprehensive review of the literature on usability and user experience in games. The result was the identification of eight core elements of player enjoyment in games - concentration, challenge, skills, control, clear goals, feedback, immersion, and social interaction. These core elements were observed to overlap closely with, and were subsequently mapped to, the elements of flow [13]. This structure formed the foundation of a new model of player enjoyment in games, called GameFlow. Each element of the GameFlow model consists of an overall goal and a set of criteria that can be used to design and evaluate games with respect to player enjoyment. Since the original publication of the GameFlow model in 2005, it has been extensively used throughout games research and development communities.

Our previous work investigated the relationship between GameFlow and other player experience measures [48]. In this work, we analysed the overlaps and divergences between the conceptual constructs of GameFlow and selected player experience measures and the different roles each instrument could play in game development. We observed that ratings alone are unlikely to provide a complete understanding of why and how a game is providing an enjoyable experience or to provide all available insights to a developer who is trying to improve their game. We proposed that given the already extensive number of player experience measures available for researchers that a key opportunity for use and future development of the GameFlow model lies in supporting developers and researchers to inquire into

Permission to make digital or hard copies of part or all of this work for personal or classroom use is granted without fee provided that copies are not made or distributed for profit or commercial advantage and that copies bear this notice and the full citation on the first page. Copyrights for third-party components of this work must be honored. For all other uses, contact the owner/author(s).

(C) 2020 Copyright held by the owner/author(s).

Manuscript submitted to ACM 
how and why a game is or is not providing, or affording, an enjoyable experience, via heuristics. We concluded that GameFlow provides a unique contribution as a design and evaluation tool for in-depth inquiry, which works alongside validated player experience measures, and that valuable future work lies in further developing the GameFlow model to this purpose.

Previous work has also evaluated and critiqued the GameFlow model [7, 11, 23, 24, 43] and tested the applicability of the model to various contexts to identify any weaknesses of the model [47-53]. Our aim is to update the GameFlow model and develop a revised tool that addresses the previous recommendations and identified issues. However, we also want to ensure that GameFlow fills a gap in the field and makes a defined contribution, rather than just adding to the already crowded field of player experience measures. Our first step is to survey the field of previous GameFlow applications, to gain a full understanding of how and where it has been used, and where its most valuable future contributions lie. As such, in this paper, we survey the 205 applications of GameFlow over the last 15 years and report on the types of applications, platforms, domains, audience, and usage of the model. This work will lay the foundations for targeting the next version of the model towards how the model has been, can be, and should be used, and to define how this fits within the broader landscape of player experience tools.

\section{FLOW AND GAMEFLOW}

Csikszentmihalyi's concept of flow [13] seeks to understand what makes experiences enjoyable and why people engage in certain activities. Csikszentmihalyi began his research with people who spend large amounts of time and effort on activities that are difficult, but provide no external rewards, such as composers, chess players, and rock climbers [12]. His later studies were conducted with a broader set of people, asking them to describe how it felt when their lives were at their fullest and when what they did was most enjoyable. He found that optimal experience, or flow, is the same around the world and irrespective of social class, age, or gender. Very different activities are described in similar ways when they are being enjoyed. Flow is an experience "so gratifying that people are willing to do it for its own sake, with little concern for what they will get out of it, even when it is difficult or dangerous" [13]. The key element in flow is that it is an end in itself - the activity is intrinsically rewarding and autotelic. In flow, the goal is often an "excuse" for the process [39].

Due to the lack of existing frameworks for evaluating enjoyment in games at the time, Sweetser and Wyeth [55] conducted a comprehensive review of the literature on usability and user experience in games to determine the key elements of player enjoyment in video games. They identified eight core elements of player enjoyment in games: concentration, challenge, skills, control, clear goals, feedback, immersion, and social interaction. Sweetser and Wyeth observed that these core elements overlapped closely with the elements of flow and subsequently mapped their core elements of player enjoyment to the elements of flow, as shown in Table 1 . This structure formed the foundation of a new model of player enjoyment in games, called GameFlow.

The GameFlow elements are all closely interrelated and interdependent. In summary, games must hold the player's attention through a high workload, with tasks that are sufficiently challenging to be enjoyable. The player must be skilled enough to undertake the challenging tasks, the tasks must have clear goals so that the player can complete the tasks, and the player must receive feedback on progress towards completing the tasks. If the player is sufficiently skilled and the tasks have clear goals and feedback, then the player will feel a sense of control over the task. The resulting feeling for the player is total immersion or absorption in the game, which causes the player to lose awareness of everyday life, concern for themselves, and alters their sense of time. The final element of player enjoyment, social interaction, does not map to the elements of flow, but features strongly in the player experience literature [8, 14]. Each 
Table 1. Mapping of flow to GameFlow elements [55].

\begin{tabular}{ll}
\hline GameFlow & Flow \\
\hline The Game & A task that can be completed \\
Concentration & Ability to concentrate on the task \\
Challenge/Player Skills & Perceived skills should match challenges and both must exceed a certain threshold \\
Control & Allowed to exercise a sense of control over actions \\
Clear Goals & The task has clear goals \\
Feedback & The task provides immediate feedback \\
Immersion & Deep but effortless involvement, reduced concern for self and sense of time \\
Social Interaction & No corresponding element of flow \\
\hline
\end{tabular}

element of the GameFlow model consists of an overall goal and a set of criteria that can be used to design and evaluate games with respect to player enjoyment.

\section{PREVIOUS WORK}

The GameFlow model was designed to be a general model of player enjoyment, applicable to all game genres and platforms [51]. A number of extensions and derivations of the GameFlow model have been developed to target GameFlow towards more specific experiences, including:

- EGameFlow, a questionnaire developed to evaluate e-learning games [20].

- Pervasive GameFlow (PGF), a model to evaluate player enjoyment of pervasive games [26, 27].

- RTS-GameFlow, a model developed specifically for real-time strategy games [16].

- ARG-PGF, an extension the PGF model to apply to alternate reality games [32,33].

- Social GameFlow, a model to conceptualise how games might foster flow and cooperative learning through social play [5].

- MIU-GameFlow, a model for enjoyable playing experiences for motor impaired users [65].

- A number of other models and measures draw on GameFlow, along with other constructs, including the Playful Experience Framework [30] and the Instructional Game Evaluation Framework [56].

In addition to the many applications of the GameFlow model, there has been a small amount of previous work that has aimed to test the applicability of the model to various contexts and to identify any weaknesses of the model, which has included:

- Evaluating an online strategy game under development with different stakeholders (developer, players, journalists, researchers) by conducting expert reviews using Gameflow, alongside other player experience measures [47-49].

- Evaluating virtual reality (VR) versus non-VR games by conducting expert reviews using GameFlow criteria and analysing game reviews using GameFlow as a theoretical framework [53, 54].

- Evaluating first person shooter games on console and adventure games on mobile by conducting expert reviews using GameFlow criteria [51].

- Analysing professional game reviews for real-time strategy games using GameFlow as a theoretical framework $[50,52]$.

- Evaluating real-time strategy games on PC by conducting expert reviews using GameFlow criteria [55]. 
The GameFlow model has also been evaluated and critiqued in the literature, particularly focusing on the inclusion of the Social Interaction element [11], the relationship between Social Interaction and Immersion [23], the division between Player Skills and Challenge [7], the conceptualisation and measurement of immersion [7, 24], and the GameFlow model's connection to the concept of flow [11, 43]. Previous research has found that the Immersion criteria are difficult to assess via expert review and that they might not apply to all types of games [52, 55]. It has also been identified that some GameFlow elements relate to the game and some relate to the player experience [51]. A number of recommendations have been made for improvements to GameFlow [47, 49], including:

- For evaluation purposes, the criteria should be written as statements about the game against which the reviewer can rate their agreement, rather than heuristic-style statements of what games should provide.

- Unclear words should be removed or made clear in the context of the statement (i.e., "stimuli" in Concentration criteria and "errors" in Control criteria).

- Each criterion should be simplified to contain a single statement that can be given a rating, which will involve splitting some criteria (e.g., criteria in Concentration, Player Skills, Social Interaction).

- Criteria should be revised to remove language that is outdated or game-type-specific (e.g., "manual" in Player Skills criteria, "shell" and "starting, stopping, saving" in Control criteria).

- The inclusion of the Immersion element needs to be reconsidered, with the likely removal of this element or, otherwise, significant reconceptualisation.

- It should be made clearer that elements and criteria are optional and that not all criteria apply to all games and that criteria can be given an N/A rating.

- The criteria should be unified in whether they are referring to the game, the player, the player experience, or what the game provides or affords.

GameFlow was originally developed in recognition of the absence of an accepted model of enjoyment in games [55]. The goal of GameFlow was to integrate the existing disparate heuristics into a validated model that can be used to design, evaluate, and understand enjoyment in games. In the intervening years, there have also been a number of different models and measures that have emerged. It is therefore important that any changes and updates to GameFlow take into consideration the full landscape of player experience tools currently available. Some of the more prevalent measures include:

- The Player Experience Inventory (PXI), which measures player experiences at the level of functional and psychosocial consequences [1].

- The Player Experience of Need Satisfaction (PENS) measure, which is based on self-determination theory [46].

- The Game Engagement Questionnaire (GEQ), which measures engagement in video game-playing based on absorption, flow, presence, and immersion [9].

- The Game Immersion Questionnaire (GIQ), which includes engagement, engrossment, and immersion [10].

- The Immersive Experience Questionnaire (IEQ), which measures immersion in games based on involvement, dissociation, challenge, and control [28].

- The Game Experience Questionnaire (GEQ), which measures user experience in games including competence, immersion, flow, tension, challenge, and affect [24]. 
Table 2. Types of applications that have used the GameFlow model.

\begin{tabular}{lll}
\hline Type & Number & Examples \\
\hline Serious Games & 103 & VR exergames [6], Exercube [35], Virtual Showdown [61], Walk after stroke [34] \\
Games & 73 & Time pressure [64], Alternate reality games [33], Tainted olfactory game [44] \\
Applications & 29 & Worlds of Information [25], La Camera Insabbiata [22], Orientation Passport [19] \\
\hline
\end{tabular}

Table 3. Domains of applications that have used the GameFlow model.

\begin{tabular}{lll}
\hline Domain & Number & Examples \\
\hline Education & 78 & Nutrition education [29], Language game [38], HackFlow [40], Cultural game [31] \\
Entertainment & 74 & Time pressure [64], Alternate reality games [33], Digital multitasking [60] \\
Health & 39 & Exercube [35], Virtual Showdown [61], Walk after stroke [34], Sports wearable [21] \\
Other & 14 & MapLens [37], Orientation Passport [19], Cybersecurity [58], Data generation [3] \\
\hline
\end{tabular}

\section{METHOD}

In order to gain a full understanding of how and where the GameFlow model has been applied over the last 15 years, we surveyed the 2445 citations to the GameFlow model, according to Google Scholar (as of 17 August 2020). We examined the papers to identify whether they had used GameFlow in some manner (e.g., for evaluation or design) or whether the citations were passing references or discussion of the model without application. Only papers published in English were examined. We found that 205 papers used the GameFlow model, either for design, evaluation, or analysis of a particular application. Subsequently, we went through the 205 papers to classify their types of applications, platforms, domain, audience, and GameFlow usage. The results of this classification are reported in the following section.

\section{RESULTS}

Figure 1 shows the number of citations and applications of GameFlow per year since its first publication in 2005 until 2019 (2020 is excluded as it is incomplete). The majority of applications (see Table 2) were to Serious Games (N=103), followed by Games ( $\mathrm{N}=73$ ), Applications and Experiences $(\mathrm{N}=29$, of which 13 were Gamified). The largest domains (see Table 3) were Education ( $\mathrm{N}=78$, including training) and Entertainment $(\mathrm{N}=74)$, followed by Health ( $\mathrm{N}=39$, including exercise, rehabilitation, and treatment). A small number were for Utility $(\mathrm{N}=11)$ and Research $(\mathrm{N}=3)$. Most applications were designed for or tested with a general population or university students. For applications that were designed for or tested with specified groups (see Table 4), the most were for Children (N=36), followed by Disabled People $(\mathrm{N}=12$, of which 6 were also Children), Seniors $(\mathrm{N}=9)$, and Stroke Patients $(\mathrm{N}=5)$. Most applications used GameFlow for evaluation ( $\mathrm{N}=163)$, followed by design $(\mathrm{N}=31)$, or a theoretical framework for new models $(\mathrm{N}=12)$ or research $(\mathrm{N}=8)$. Of the applications that used GameFlow for design or evaluation, a small number used it for both (N=11). GameFlow was mostly used in full or part as a questionnaire $(\mathrm{N}=114)$, as an analytical tool $(\mathrm{N}=34)$, as heuristics $(\mathrm{N}=17)$, and to structure interviews $(\mathrm{N}=6)$. Most applications were web-based and/or tested on PC. Of the more specialised platforms (see Table 5), the most common were Mobile ( $\mathrm{N}=39)$ and Extended Reality $(\mathrm{N}=33)$, including Mixed Reality $(\mathrm{N}=19$, including camera-based and projections), Virtual Reality $(\mathrm{N}=8)$, and Augmented Reality $(\mathrm{N}=6)$. Other platforms include games Consoles $(\mathrm{N}=15)$, Robots $(\mathrm{N}=5)$, Handheld $(\mathrm{N}=4)$, Custom $(\mathrm{N}=4)$, Alternate Reality Games $(\mathrm{N}=4)$, Tangibles $(\mathrm{N}=4)$, and Wearables $(\mathrm{N}=3)$. 


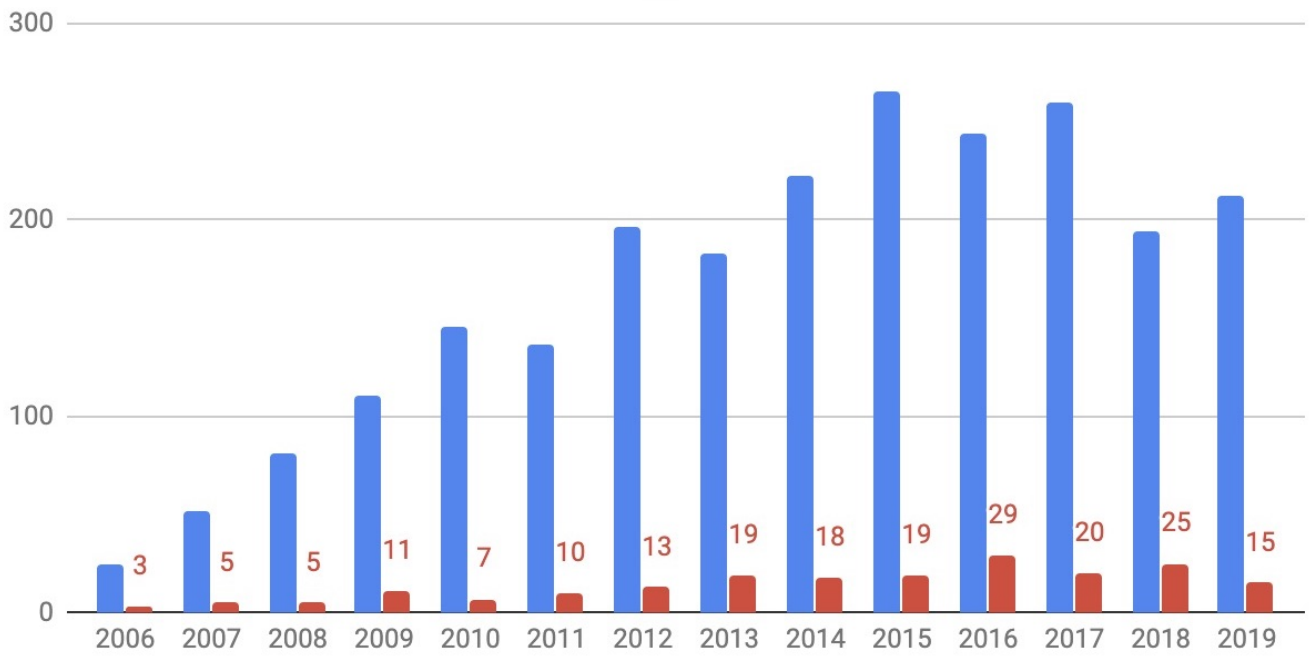

Fig. 1. Number of citations and applications of GameFlow per year since publication.

Table 4. Audience of applications that have used the GameFlow model, not including general population and university students.

\begin{tabular}{lll}
\hline Audience & Number & Examples \\
\hline Children & 36 & Nutrition education [29], Marbowl [18], Language game [38], Environment [59] \\
Disabled People & 12 & Virtual Showdown [61], Eyes-Free Yoga [45], Augmented Biofeedback Training [2] \\
Seniors & 9 & Exergame [36], Limb mobility [4], Cognitive abilities [15], Assistive robot [63] \\
\hline
\end{tabular}

Table 5. Platforms of applications that have used the GameFlow model, not including PC, web-based, and unspecified.

\begin{tabular}{lll}
\hline Platform & Number & Examples \\
\hline Mobile & 39 & MapLens [37], Walk after stroke [34], Biofeedback game [62], Cultural game [31] \\
Extended Reality & 33 & VR exergames [6], VR artwork [22], Attention training [41], AR mobile games [42] \\
Other & 39 & Sports wearable [21], Interactive Fruit Panel [17], Physical therapy wearable [57] \\
\hline
\end{tabular}

\section{DISCUSSION}

GameFlow is a widely used and accepted model of enjoyment in games. Over the last 15 years, its application and usage has been documented in 205 published research papers, with over 2000 additional papers citing the original work. In this paper, we surveyed the 205 papers and reported on the types, domain, audience, and platform of the applications that the GameFlow model has been used to design, evaluate, and analyse. We found that half of the applications of GameFlow were to Serious Games, with most of these relating to education and training, followed by health and fitness. About a third of the applications were to games with the primary purpose of entertainment. The remaining applications were to non-game applications and experiences. 
Our survey has demonstrated the extensive usage of the GameFlow model beyond the model's original purposes of designing and evaluating games for enjoyment. The goal of our ongoing work is to update and improve the GameFlow model, to incorporate recommendations and to ensure that it is fit for purpose and fulfilling a proven need in research and development communities. Based on our survey, it is evident that future versions of the GameFlow model should take into consideration the broad range of applications, with a particular focus on Serious Games for education and health. Our processes to update and revise the model will need to include consultation and testing with these communities and applications.

Another point to note is that although the GameFlow model does not include a validated measure, over half of applications used it as a questionnaire or as the basis for a questionnaire, either in full or in part. This could represent a lack of awareness of the various validated measures or that it is desirable and convenient to use a tool that offers a model to understand enjoyment, a set of heuristics for designing enjoyable experiences, and a set of questions for measuring the effectiveness of the design. The usage of the GameFlow model has increased over time, despite many other measures becoming available in this time. Based on our survey of how the model has been used and the trends over time, our ongoing work will need to consider how people are applying the model and how they can be supported to apply the model over the full life cycle of their research and development. We propose that it would be useful to provide researchers and developers, particularly those who are not primarily game designers or user research experts, with a suite of tools (model, measure, heuristics) and a clear process for how to use these tools at different stages of their work.

A final point of interest is that the platforms and audiences for applications of GameFlow have grown and expanded over time. Many papers surveyed had developed tailored versions of GameFlow to be used by children, converting questions to be child-friendly and using scales for children (e.g., smiley-o-meters $[18,38]$ ). There is also a growing body of work that is targeted towards new technologies and forms of interaction, such as robots, wearables, and extended reality. Our ongoing work will also need to take into consideration the diverse audiences and platforms that GameFlow is being used for, which extend far beyond the PC games examined in the original work.

\section{CONCLUSIONS}

The aim of the work reported in this paper was to survey the set of papers that have applied the GameFlow model for design, evaluation, and analysis to develop an understanding of how, where, and why the GameFlow model has been applied in the last 15 years. Our results show that the applications are diverse in terms of application type, domain, audience, platform, and usage of the model. The research and development activities that are making use of the GameFlow model stretch far beyond the aims of the original paper to service a broad range of games for enjoyment, which at the time was predominantly PC games. Our ongoing work to revise and update the model to best service the communities that are using it will incorporate the insights provided by this survey. We will look to develop a suite of tools and clear processes that can support researchers and developers in a broad range of domains with varying expertise to incorporate elements of GameFlow into their projects at different stages. It is exciting to see such a diverse group of people leveraging enjoyment and game design heuristics to improve engagement with different experiences.

\section{REFERENCES}

[1] Vero Vanden Abeele, Katta Spiel, Lennart Nacke, Daniel Johnson, and Kathrin Gerling. 2020. Development and validation of the player experience inventory: A scale to measure player experiences at the level of functional and psychosocial consequences. International fournal of Human-Computer Studies 135 (2020), 102370. https://doi.org/10.1016/j.ijhcs.2019.102370 
[2] Reem M Alwhaibi, Reham S Alsakhawi, and Safaa M ElKholi. 2020. Augmented Biofeedback Training with Physical Therapy Improves Visual-Motor Integration, Visual Perception, and Motor Coordination in Children with Spastic Hemiplegic Cerebral Palsy: A Randomised Control Trial. Physical occupational therapy in pediatrics 40, 2 (2020), 134-151. https://doi.org/10.1080/01942638.2019.1646375

[3] Saeed Amiri-Chimeh, Hassan Haghighi, Mojtaba Vahidi-Asl, Kamyar Setayesh-Ghajar, and Farshad Gholami-Ghavamabad. 2017. Rings: A Game with a Purpose for Test Data Generation. Interacting with Computers 30, 1 (02 2017), 1-30. https://doi.org/10.1093/iwc/iww043

[4] Mahmoud Awad, Stuart Ferguson, and Cathy Craig. 2014. Designing games for older adults: an affordance based approach. In 2014 IEEE 3nd International Conference on Serious Games and Applications for Health (SeGAH). 1-7.

[5] Christine M. Bachen and Chad Raphael. 2011. Social Flow and Learning in Digital Games:A Conceptual Model and Research Agenda. Springer London, London, 61-84. https://doi.org/10.1007/978-1-4471-2161-9_5

[6] Soumya C. Barathi, Michael Proulx, Eamonn O’Neill, and Christof Lutteroth. 2020. Affect Recognition Using Psychophysiological Correlates in High Intensity VR Exergaming. In Proceedings of the 2020 CHI Conference on Human Factors in Computing Systems (Honolulu, HI, USA) (CHI '20). ACM, New York, NY, USA, 1-15. https://doi.org/10.1145/3313831.3376596

[7] Lizzy Bleumers, An Jacobs, and Tim Van Lier. 2010. Criminal Cities and Enchanted Forests: A User-Centred Assessment of the Applicability of the Pervasive GameFlow Model. In Proceedings of the 3rd International Conference on Fun and Games (Leuven, Belgium) (Fun and Games '10). ACM, New York, NY, USA, 38-47. https://doi.org/10.1145/1823818.1823822

[8] Matthew Bond and Russell Beale. 2009. What Makes a Good Game? Using Reviews to Inform Design. In Proceedings of the 23rd British HCI Group Annual Conference on People and Computers: Celebrating People and Technology (Cambridge, United Kingdom) (BCS-HCI '09). BCS Learning Development Ltd., Swindon, GBR, 418-422.

[9] Jeanne H. Brockmyer, Christine M. Fox, Kathleen A. Curtiss, Evan McBroom, Kimberly M. Burkhart, and Jacquelyn N. Pidruzny. 2009. The development of the Game Engagement Questionnaire: A measure of engagement in video game-playing. Fournal of Experimental Social Psychology 45, 4 (2009), 624 - 634. https://doi.org/10.1016/j.jesp.2009.02.016

[10] M.-T. Cheng, H.-C. She, and L.A. Annetta. 2015. Game immersion experience: its hierarchical structure and impact on game-based science learning. fournal of Computer Assisted Learning 31, 3 (2015), 232-253. https://doi.org/10.1111/jcal.12066

[11] Ben Cowley, Darryl Charles, Michaela Black, and Ray Hickey. 2008. Toward an Understanding of Flow in Video Games. Comput. Entertain. 6, 2, Article 20 (July 2008), 27 pages. https://doi.org/10.1145/1371216.1371223

[12] Mihaly Csikszentmihalyi. 1975. Beyond Boredom and Anxiety. Jossey-Bass Publishers, Washington.

[13] Mihaly Csikszentmihalyi. 1991. Flow: The Psychology of Optimal Experience. Harper Perennial, New York.

[14] Yvonne A. W. De Kort and Wijnand A. Ijsselsteijn. 2008. People, Places, and Play: Player Experience in a Socio-Spatial Context. Comput. Entertain. 6, 2, Article 18 (July 2008), 11 pages. https://doi.org/10.1145/1371216.1371221

[15] Elena de la Guía, María Dolores Lozano, and Víctor M. R. Penichet. 2014. Increasing Engagement in Elderly People through Tangible and Distributed User Interfaces. In Proceedings of the 8th International Conference on Pervasive Computing Technologies for Healthcare (Oldenburg, Germany) (PervasiveHealth '14). ICST, Brussels, BEL, 390-393. https://doi.org/10.4108/icst.pervasivehealth.2014.255361

[16] Sha Ding, Ningjiu Tang, Tao Lin, and Shiyuan Zhao. 2009. RTS-GameFlow: A New Evaluation Framework for RTS Games. In 2009 International Conference on Computational Intelligence and Software Engineering. 1-4. https://doi.org/10.1109/CISE.2009.5363526

[17] Iván Durango, Alicia Carrascosa, Victor M. R. Penichet, and José A. Gallud. 2015. Tangible Serious Games with Real Objects to Support Therapies for Children with Special Needs. In Proceedings of the XVI International Conference on Human Computer Interaction (Vilanova i la Geltru, Spain) (Interacción '15). ACM, New York, NY, USA, Article 41, 2 pages. https://doi.org/10.1145/2829875.2829910

[18] Jabe Piter Faber and Elise Van Den Hoven. 2012. MARBOWL: Increasing the Fun Experience of Shooting Marbles. Personal Ubiquitous Comput. 16, 4 (April 2012), 391-404. https://doi.org/10.1007/s00779-011-0405-1

[19] Zachary Fitz-Walter, Dian Tjondronegoro, and Peta Wyeth. 2011. Orientation Passport: Using Gamification to Engage University Students. In Proceedings of the 23rd Australian Computer-Human Interaction Conference (Canberra, Australia) (OzCHI '11). ACM, New York, NY, USA, 122-125. https://doi.org/10.1145/2071536.2071554

[20] Fong-Ling Fu, Rong-Chang Su, and Sheng-Chin Yu. 2009. EGameFlow: A scale to measure learners' enjoyment of e-learning games. Computers Education 52, 1 (2009), 101 - 112. https://doi.org/10.1016/j.compedu.2008.07.004

[21] Hayati Havlucu, Terry Eskenazi, Bariş Akgün, Mehmet Cengiz Onbaşlı, Aykut Coşkun, and Oğuzhan Özcan. 2018. Flow State Feedback Through Sports Wearables: A Case Study on Tennis. In Proceedings of the 2018 Designing Interactive Systems Conference (Hong Kong, China) (DIS '18). ACM, New York, NY, USA, 1025-1039. https://doi.org/10.1145/3196709.3196807

[22] Meng-Hsuan Huang and Saiau-Yue Tsau. 2018. A Flow Experience Analysis on the Virtual Reality Artwork: La Camera Insabbiata. In Proceedings of the International Conference on Machine Vision and Applications (Singapore, Singapore) (ICMVA 2018). ACM, New York, NY, USA, 51-55. https://doi.org/10.1145/3220511.3220514

[23] Sarah Hudson, Sheila Matson-Barkat, Nico Pallamin, and Guillaume Jegou. 2019. With or without you? Interaction and immersion in a virtual reality experience. Journal of Business Research 100 (2019), 459 - 468. https://doi.org/10.1016/j.jbusres.2018.10.062

[24] W.A. IJsselsteijn, Y.A.W. Kort, de, K. Poels, A. Jurgelionis, and F. Bellotti. 2007. Characterising and measuring user experiences in digital games. In Proceedings of the International Conference on Advances in Computer Entertainment Technology (ACE 2007), June 13-15, 2007, R. Bernhaupt and M. Tscheligi (Eds.). 1-4. 
[25] Giulio Jacucci, Ann Morrison, Gabriela T. Richard, Jari Kleimola, Peter Peltonen, Lorenza Parisi, and Toni Laitinen. 2010. Worlds of Information: Designing for Engagement at a Public Multi-Touch Display. In Proceedings of the SIGCHI Conference on Human Factors in Computing Systems (Atlanta, Georgia, USA) (CHI '10). ACM, New York, NY, USA, 2267-2276. https://doi.org/10.1145/1753326.1753669

[26] Kalle Jegers. 2007. Pervasive Game Flow: Understanding Player Enjoyment in Pervasive Gaming. Comput. Entertain. 5, 1 (Jan. 2007), 9-es. https://doi.org/10.1145/1236224.1236238

[27] Kalle Jegers. 2009. Elaborating Eight Elements of Fun: Supporting Design of Pervasive Player Enjoyment. Comput. Entertain. 7, 2, Article 25 (June 2009), 22 pages. https://doi.org/10.1145/1541895.1541905

[28] Charlene Jennett, Anna L. Cox, Paul Cairns, Samira Dhoparee, Andrew Epps, Tim Tijs, and Alison Walton. 2008. Measuring and defining the experience of immersion in games. International fournal of Human-Computer Studies 66, 9 (2008), 641 - 661. https://doi.org/10.1016/j.ijhcs.2008.04.004

[29] Kornchulee Khanana and Effie L.-C. Law. 2013. Designing Children's Digital Games on Nutrition with Playability Heuristics. In CHI '13 Extended Abstracts on Human Factors in Computing Systems (Paris, France) (CHI EA '13). ACM, New York, NY, USA, 1071-1076. https://doi.org/10.1145/ 2468356.2468548

[30] Hannu Korhonen, Markus Montola, and Juha Arrasvuori. 2009. Understanding playful user experience through digital games. In International Conference on Designing Pleasurable Products and Interfaces, Vol. 2009. Citeseer.

[31] Ruo-Yu Li and Chang-Hwa Wang. 2020. Key factors and network model for location-based cultural mobile game design. British fournal of Educational Technology n/a, n/a (2020). https://doi.org/10.1111/bjet.12926

[32] Andrew P. Macvean and Mark O. Riedl. 2011. An Enjoyment Metric for the Evaluation of Alternate Reality Games. In Proceedings of the 6th International Conference on Foundations of Digital Games (Bordeaux, France) (FDG '11). ACM, New York, NY, USA, 277-279. https://doi.org/10.1145/2159365.2159411

[33] Andrew P. Macvean and Mark O. Riedl. 2011. Evaluating Enjoyment within Alternate Reality Games. In Proceedings of the 2011 ACM SIGGRAPH Symposium on Video Games (Vancouver, British Columbia, Canada) (Sandbox '11). ACM, New York, NY, USA, 5-10. https://doi.org/10.1145/2018556. 2018558

[34] Charlotte Magnusson, Kirsten Rassmus-Gröhn, Bitte Rydeman, and Héctor Caltenco. 2018. Walk after Stroke: Initial Development of a Step Counting Game for Stroke Survivors. In Proceedings of the 20th International Conference on Human-Computer Interaction with Mobile Devices and Services Adjunct (Barcelona, Spain) (MobileHCI '18). ACM, New York, NY, USA, 237-244. https://doi.org/10.1145/3236112.3236145

[35] Anna Lisa Martin-Niedecken, Katja Rogers, Laia Turmo Vidal, Elisa D. Mekler, and Elena Márquez Segura. 2019. ExerCube vs. Personal Trainer: Evaluating a Holistic, Immersive, and Adaptive Fitness Game Setup. In Proceedings of the 2019 CHI Conference on Human Factors in Computing Systems (Glasgow, Scotland Uk) (CHI '19). ACM, New York, NY, USA, 1-15. https://doi.org/10.1145/3290605.3300318

[36] Wytske Meekes and E. Stanmore. 2017. Motivational Determinants of Exergame Participation for Older People in Assisted Living Facilities: Mixed-Methods Study. Journal of Medical Internet Research 19 (2017).

[37] Ann Morrison, Antti Oulasvirta, Peter Peltonen, Saija Lemmela, Giulio Jacucci, Gerhard Reitmayr, Jaana Näsänen, and Antti Juustila. 2009. Like Bees around the Hive: A Comparative Study of a Mobile Augmented Reality Map. In Proceedings of the SIGCHI Conference on Human Factors in Computing Systems (Boston, MA, USA) (CHI '09). ACM, New York, NY, USA, 1889-1898. https://doi.org/10.1145/1518701.1518991

[38] Lisa Mörtsell. 2018. Should I stay or should I go? : Developing the Narrative model as a tool for game design. Master's thesis. Umeå University, Department of Informatics.

[39] Jeanne Nakamura and Mihaly Csikszentmihalyi. 2014. The Concept of Flow. Springer Netherlands, Dordrecht, 239-263. https://doi.org/10.1007/97894-017-9088-8_16

[40] Pia Niemelä, Tiina Partanen, Tero Toivanen, Tarmo Toikkanen, Vuokko Kangas, and Markus Översti. 2019. Code ABC Hackathons: Teachers as Tinkerers. In Digital Turn in Schools-Research, Policy, Practice, Terje Väljataga and Mart Laanpere (Eds.). Springer Singapore, Singapore, $157-169$.

[41] Cong Peng, Dangxiao Wang, Yuru Zhang, and Jing Xiao. 2019. A Visuo-Haptic Attention Training Game With Dynamic Adjustment of Difficulty. IEEE Access 7 (2019), 68878-68891.

[42] Dendi Permadi and Ahmad Rafi. 2016. Empirical Analysis of Mobile Augmented Reality Games for Engaging Users' Experience. In Intelligent and Evolutionary Systems, Kittichai Lavangnananda, Somnuk Phon-Amnuaisuk, Worrawat Engchuan, and Jonathan H. Chan (Eds.). Springer International Publishing, Cham, 343-355.

[43] Karolien Poels, Yvonne de Kort, and Wijnand Ijsselsteijn. 2007. “It is Always a Lot of Fun!”: Exploring Dimensions of Digital Game Experience Using Focus Group Methodology. In Proceedings of the 2007 Conference on Future Play (Toronto, Canada) (Future Play'07). ACM, New York, NY, USA, 83-89. https://doi.org/10.1145/1328202.1328218

[44] Nimesha Ranasinghe, Koon Chuan Raymond Koh, Nguyen Thi Ngoc Tram, Yan Liangkun, Kala Shamaiah, Siew Geuk Choo, David Tolley, Shienny Karwita, Barry Chew, Daniel Chua, and Ellen Yi-Luen Do. 2019. Tainted: An olfaction-enhanced game narrative for smelling virtual ghosts. International fournal of Human-Computer Studies 125 (2019), 7 - 18. https://doi.org/10.1016/j.ijhcs.2018.11.011

[45] Kyle Rector, Roger Vilardaga, Leo Lansky, Kellie Lu, Cynthia L. Bennett, Richard E. Ladner, and Julie A. Kientz. 2017. Design and Real-World Evaluation of Eyes-Free Yoga: An Exergame for Blind and Low-Vision Exercise. ACM Trans. Access. Comput. 9, 4, Article 12 (April 2017), 25 pages. https://doi.org/10.1145/3022729

[46] Richard M. Ryan, C. Scott Rigby, and Andrew Przybylski. 2006. The Motivational Pull of Video Games: A Self-Determination Theory Approach. Motivation and Emotion 30, 4 (2006), 344-360. https://doi.org/10.1007/s11031-006-9051-8

[47] Penny Sweetser and Daniel Johnson. 2019. Evaluating the GameFlow Model with Different Stakeholders. In Extended Abstracts of the Annual Symposium on Computer-Human Interaction in Play Companion Extended Abstracts (Barcelona, Spain) (CHI PLAY '19 Extended Abstracts). ACM, New 
York, NY, USA, 697-703. https://doi.org/10.1145/3341215.3356286

[48] Penny Sweetser and Daniel Johnson. 2019. GameFlow and Player Experience Measures: An Initial Comparison of Conceptual Constructs. In Proceedings of the 31st Australian Conference on Human-Computer-Interaction (Fremantle, WA, Australia) (OZCHI'19). ACM, New York, NY, USA, 317-321. https://doi.org/10.1145/3369457.3369486

[49] Penny Sweetser, Daniel Johnson, and Jay Kyburz. 2020. Evaluating GameFlow in a Multiplayer Online Strategy Game Under Development. In Proceedings of the Australasian Computer Science Week Multiconference (Melbourne, VIC, Australia) (ACSW'20). ACM, New York, NY, USA, Article 47, 10 pages. https://doi.org/10.1145/3373017.3373068

[50] Penelope Sweetser, Daniel Johnson, and Peta Wyeth. 2013. Revisiting the GameFlow Model with Detailed Heuristics. The fournal of Creative Technologies 3 (May 2013). https://ojs.aut.ac.nz/journal-of-creative-technologies/index.php/JCT/article/view/16

[51] Penelope Sweetser, Daniel Johnson, Peta Wyeth, Aiman Anwar, Yan Meng, and Anne Ozdowska. 2017. GameFlow in Different Game Genres and Platforms. Comput. Entertain. 15, 3, Article 1 (April 2017), 24 pages. https://doi.org/10.1145/3034780

[52] Penelope Sweetser, Daniel Johnson, Peta Wyeth, and Anne Ozdowska. 2012. GameFlow Heuristics for Designing and Evaluating Real-Time Strategy Games. In Proceedings of The 8th Australasian Conference on Interactive Entertainment: Playing the System (Auckland, New Zealand) (IE '12). ACM, New York, NY, USA, Article 1, 10 pages. https://doi.org/10.1145/2336727.2336728

[53] Penny Sweetser and Zane Rogalewicz. 2020. Affording Enjoyment in VR Games: Possibilities, Pitfalls, and Perfection. In Proceedings of the 32nd Australian Conference on Human-Computer-Interaction (Sydney, NSW, Australia) (OZCHI'20). ACM, New York, NY, USA.

[54] Penny Sweetser, Zane Rogalewicz, and Qingyang Li. 2019. Understanding Enjoyment in VR Games with GameFlow. In 25th ACM Symposium on Virtual Reality Software and Technology (Parramatta, NSW, Australia) (VRST '19). ACM, New York, NY, USA, Article 96, 2 pages. https: //doi.org/10.1145/3359996.3364800

[55] Penelope Sweetser and Peta Wyeth. 2005. GameFlow: A Model for Evaluating Player Enjoyment in Games. Comput. Entertain. 3,3 (July 2005), 3. https://doi.org/10.1145/1077246.1077253

[56] Jean Lee Tan, Dion Hoe-Lian Goh, Rebecca P Ang, and Vivien S Huan. 2010. Usability and Playability Heuristics for Evaluation of an Instructional Game. In Proceedings of E-Learn: World Conference on E-Learning in Corporate, Government, Healthcare, and Higher Education 2010, Jaime Sanchez and Ke Zhang (Eds.). Association for the Advancement of Computing in Education (AACE), Orlando, Florida, USA, 363-373. https://www.learntechlib. org/p/35570

[57] Andrea Torres, Gustavo López, and Luis A. Guerrero. 2016. Using Non-Traditional Interfaces to Support Physical Therapy for Knee Strengthening. Journal of Medical Systems 40, 9 (2016), 194. https://doi.org/10.1007/s10916-016-0550-1

[58] Adam Trowbridge, Filipo Sharevski, and Jessica Westbrook. 2018. Malicious User Experience Design Research for Cybersecurity. In Proceedings of the New Security Paradigms Workshop (Windsor, United Kingdom) (NSPW '18). ACM, New York, NY, USA, 123-130. https://doi.org/10.1145/3285002. 3285010

[59] Chung-Hsiang Wang, Ko-Chiu Wu, and Saiau-Yue Tsau. 2019. Flow Learning Experience: Applying Marketing Theory to Serious Game Design. fournal of Educational Computing Research 57, 2 (2019), 417-447. https://doi.org/10.1177/0735633117752454

[60] Hao Wang, Chien-Wen Yang, and Chun-Tsai Sun. 2020. Measuring and Comparing Immersion in Digital Media Multitasking. 123-146. https: //doi.org/10.4018/978-1-7998-2637-8.ch007

[61] Ryan Wedoff, Lindsay Ball, Amelia Wang, Yi Xuan Khoo, Lauren Lieberman, and Kyle Rector. 2019. Virtual Showdown: An Accessible Virtual Reality Game with Scaffolds for Youth with Visual Impairments. In Proceedings of the 2019 CHI Conference on Human Factors in Computing Systems (Glasgow, Scotland Uk) (CHI '19). ACM, New York, NY, USA, Article 141, 15 pages. https://doi.org/10.1145/3290605.3300371

[62] Thomas Wollmann, Farhad Abtahi, Aboozar Eghdam, Fernando Seoane, Kaj Lindecrantz, Martin Haag, and Sabine Koch. 2016. User-Centred Design and Usability Evaluation of a Heart Rate Variability Biofeedback Game. IEEE Access 4 (2016), 5531-5539.

[63] Y-H Wu, Jérémy Wrobel, Victoria Cristancho-Lacroix, Laila Kamali, Mohamed Chetouani, Dominique Duhaut, Brigitte Le Pévédic, Céline Jost, Vincent Dupourque, Meftah Ghrissi, et al. 2013. Designing an assistive robot for older adults: The ROBADOM project. IRBM 34, 2 (2013), 119 - 123. https://doi.org/10.1016/j.irbm.2013.01.003 Special issue : ANR TECSAN : Technologies for Health and Autonomy.

[64] Irem Gökçe Yildirim. 2016. Time Pressure as Video Game Design Element and Basic Need Satisfaction. In Proceedings of the 2016 CHI Conference Extended Abstracts on Human Factors in Computing Systems (San Jose, California, USA) (CHI EA '16). ACM, New York, NY, USA, 2005-2011. https://doi.org/10.1145/2851581.2892298

[65] Nurul Hidayah Mat Zain, Azizah Jaafar, and Fariza Hanis Abdul Razak. 2016. Enjoyable game design: validation of motor-impaired user GameFlow model. International fournal of Computer Theory and Engineering 8, 2 (2016), 116. 